\title{
PERENCANAAN BISNIS DESAIN WEBSITE
}

\author{
Irvan Sunardi \\ Program Studi Magister Manajemen Universitas Tarumanagara \\ irvan.sunardi@yahoo.com
}

Masuk : 05-06-2020, revisi : 07-07-2020 diterima untuk diterbitkan : 07-07-2020

\begin{abstract}
Website design is the process of planning, conceptualizing, and managing content intended for the Internet. Modern website design goes beyond how things look (aesthetically) to include the way things work (functionality). Website design is not limited to website sites because it includes other uses such as web applications, mobile applications, and user interface designs. "Website Design Business Planning" is a business plan in the creative services industry. With the advancement of digital technology \& the era of the industrial revolution 4.0 made a disruptive era. Where the internet becomes very important in the progress of a business that is running or will be made. Innovation, creativity, the use of technology, and don't be easily satisfied are the keys to surviving the era disruption. The use of the internet seems to be a main menu in the daily routine. Everyone gets a lot of new information from the use of the internet. Based on the results of the analysis and discussion, it can be concluded that this business is feasible to be realized on the basis of considerations, among others, because the market potential of website design business increases. Financial planning that shows that this business will provide profits for investors and deserve to be realized. Analysis of financial instruments consisting of Payback Period which shows the number 1.38, Net Present Value value of Rp. $1,811,399,733$, - or greater than zero shows that this investment can produce income levels that exceed the requested level and the Internal Rate of Return is $86 \%$ higher than the deposit interest rate.
\end{abstract}

Abstrak: Desain website adalah proses perencanaan, konseptualisasi, dan mengatur konten yang ditujukan untuk internet. Desain website modern melampaui bagaimana hal-hal terlihat (estetika) untuk memasukkan cara kerja (fungsionalitas). Desain website tidak terbatas pada situs website karena mencakup penggunaan lain seperti aplikasi web, aplikasi seluler, dan desain antarmuka pengguna. "Perencanaan Bisnis Desain Website" adalah rencana bisnis di bidang industri kreatif jasa teknologi. Dengan kemajuan teknologi digital \& era revolusi industri 4.0 membuat disruptif era. Dimana internet menjadi sangat penting dalam kemajuan bisnis yang berjalan maupun yang akan dibuat. Inovasi, kreatifitas, penggunaan teknologi, \& jangan mudah merasa puas adalah kunci bertahan menghadapi disrupsi era. Penggunaan internet seolah- olah menjadi suatu menu utama dikebiasaan rutin sehari- hari. Semua orang mendapatkan banyak informasi baru dari penggunaan internet. Berdasarkan hasil analisa dan pembahasan, maka dapat disimpulkan bahwa bisnis ini layak direalisasikan dengan dasar pertimbangan antara lain karena potensi pasar bisnis desain website meningkat. Perencanaan keuangan yang menunjukan bahwa bisnis ini akan memberikan profit bagi investor dan layak untuk direalisasikan. Analisa instrument keuangan yang terdiri dari Payback Period yang menunjukan angka 1,38, nilai Net Present Value dengan nilai Rp. 1.811.399.733,- atau lebih besar dari nol menunjukan investasi ini dapat menghasilkan tingkat penghasilan yang melebihi tingkat yang diminta dan nilai Internal Rate of Return sebesar $86 \%$ lebih tinggi dari suku bunga simpanan.

Keywords: Desain Website, Business Plan, Innovation, Financial Aspect, Payback Period, Net Present Value, Internal Rate of Return 


\section{PENDAHULUAN}

Era revolusi industri 4.0 menjadikan ekonomi kreatif menjadi salah satu isu strategis yang layak mendapatkan pengaruh utama sebagai pilihan strategi memenangkan persaingan global, ditandai dengan terus dilakukannya inovasi dan kreativitas guna meningkatkan nilai tambah ekonomi melalui kapitalisasi ide kreatif. Peluang ekonomi kreatif di pasar Internasional, John Howkins dalam buku The Creative Economy: How People Make Money from Ideas (Penguin Books,2001). Januari tahun 2000 perkiraan nilai ekonomi kreatif di dunia adalah sebesar US\$ 2,24 Triliun dan tumbuh sebesar 5\% per tahunnya. Jika diproyeksikan hingga tahun 2020 dengan tingkat pertumbuhan yang sama yaitu 5\%, maka nilai ekonomi kreatif ini akan mencapai US\$ 6,1 Triliun (Howkins, 2001). Berdasarkan World Bank, tahun 1999 GNP dunia mencapai sebesar US\$ 30,2 Triliun sehingga ekonomi kreatif berkontribusi 7,3\% terhadap ekonomi global. (Howkins, 2001).

Pada tahun 2018 dibawah kepemerintahan Presiden Jokowi Widodo kembali dirancang dan dikeluarkan Peraturan Presiden nomor 142 tahun 2018 tentang Rencana Induk Pengembagan Ekonomi Kreatif Nasional 2018-2025 (Perpres Rindekraf) sebagai landasan pengembangan ekonomi kreatif di Indonesia. Kemudian 26 September 2019 disusul disahkannya RUU Ekonomi Kreatif oleh DPR yaitu, Undang-undang Republik Indonesia nomor 24 tahun 2019 yang berfungsi untuk mengatur ekonomi kreatif dari hulu sampai ke hilir dengan prinsipnya tidak diarahkan untuk membatasi kreativitas para pelaku ekonomi kreatif. Hal ini mendorong beberapa pengusaha untuk bergerak dan mengembangkan usaha dibidang industri kreatif.

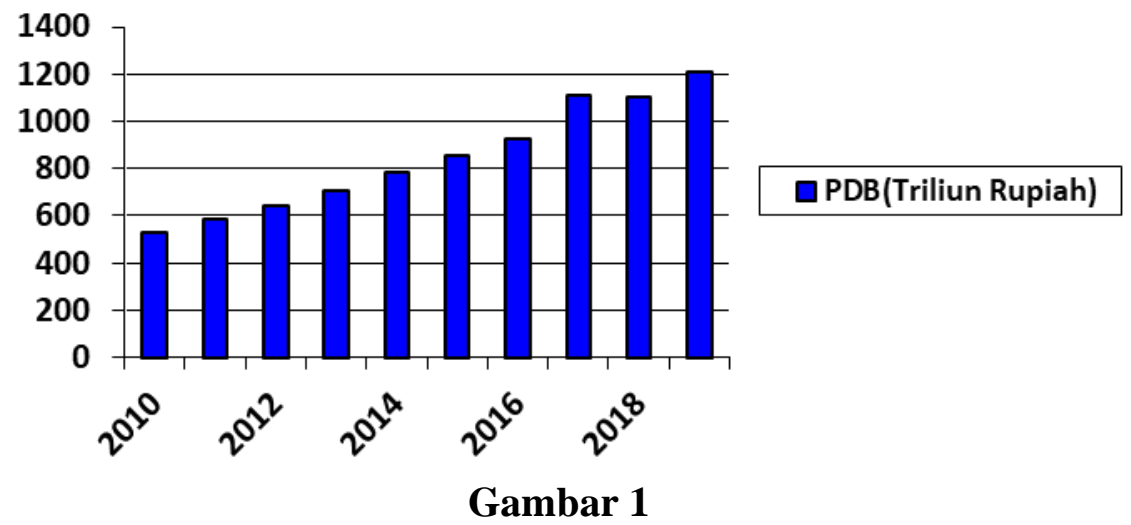

Pertumbuhan PDB Ekonomi Kreatif 2010- 2019

Diakhir 2018 menurut data BPPT yang diekstrapolasi BPS sumbangan ekonomi kreatif Indonesia itu Rp. 1.105 trilliun. Berikutnya diakhir tahun 2019 PDB ekonomi kreatif Indonesia Rp. 1.211 trilliun. Dengan melihat fenomena pertumbuhan PDB ekonomi kreatif Indonesia dari 2010-2019. Maka industry ekonomi kreatif sangatlah menarik untuk didalami dan dikembangkan.

Rata- rata pengguna internet yang menggunakan personal computer (PC) atau tablet 4 jam 42 menit per hari, sedangkan melalui ponsel 3 jam 33 menit. Berdasarkan data situs riset internetworldsstats.com, pengguna internet di Indonesia berada pada peringkat keempat di Asia setelah Tiongkok, India, dan Jepang dengan jumlah 78 juta orang dan memiliki penetrasi $30,5 \%$.

Fenomena jumlah banyak pengguna internet ini mendorong hampir semua perusahaan membuat dan mengembangkan citra perusahaan secara digital agar dapat dikenal oleh dunia mancanegara. Salah satu cara membuat citra perusahaan secara digital adalah dengan membuat website yang berisi informasi perusahaan tersebut. Pemasaran melalui website memberikan banyak peluang bagi wirausaha dan memberikan kemampuan untuk bersaing dengan perusahaan yang lebih besar. Keberadaan website sangat efektif untuk menjangkau pasar pelanggan muda yang berpendapatan tinggi dan terdidik. Website yang berhasil bersifat 
mengundang, mudah dinavigasi, interaktif dan menawarkan nilai lebih kepada pemakainya (Scarborough et al,2009).

Banyak orang yang melihat ini sebagai sebuah peluang untuk memulai usaha baru atau bisnis baru atau dengan kata lainnya pembuatan new ventures. Salah satu bisnis yang mendukung program pemerintah pengembangan ekonomi kreatif di sektor jasa dengan memanfaatkan kemajuan teknologi dan perkembangan era digital adalah bisnis desain website. Berdasarkan latar belakang tersebut, maka dilakukan penelitian dengan judul Perencanaan Bisnis Desain Website. Pembuatan sebuah business plan dan rencana keuangan untuk bisnis desain website tujuannya adalah untuk mengetahui tingkat keberhasilan dan kelayakan dari proyeksi keuangan yang akan dibuat.

\section{Tujuan}

1. Membuat suatu rencana bisnis baru pada industri kreatif yang bergerak di bidang jasa dan teknologi berupa desain website

2. Membuka lapangan kerja untuk meningkatkan taraf hidup masyarakat.

\section{HASIL DAN PEMBAHASAN}

Berikut merupakan hasil dan pembahasan yang diperoleh melalui studi kelayakan bisnis untuk perencanaan bisnis desain website di Indonesia.

\section{Rencana Bisnis \\ Segmentation}

Menurut Kotler dan Keller (2012) segmentasi pasar adalah sebuah proses dimana mebagi sebuah pasar menjadi beberapa kelompok pembeli yang memiliki kebutuhan karakteristik atau perilaku yang berbeda, dan pembeli yang mungkin memerluan produk yang berbeda/ terpisah atau program pemasaran yang berbeda. Tugas pemasar adalah mengidentifikasi segmen dan memutuskan segmen mana yang akan dibidik bisnis ini.

Segmentasi bisnis ada pada konsumen mengenah ke atas dan para pebisnis yang membutuhkan identitas dan brand awarness secara digital.

\section{Targeting}

Menurut Kotler dan Keller (2012) market targeting adalah sebuah proses mengevaluasi ketertarikan masing- masing segmen pasar dan memilih satu atau lebih segmen pasar untuk dimasukin perusahaan.

\section{Positioning}

Kotler dan Keller (2012) menyebutkan definisi dari positioning adalah mengatur sebuah produk untuk menempati posisi yang jelas, khas dan diinginkan untuk bersaing dengan produk yang realtif untuk menempatkan produk perusahaan di benak sasaran konsumen yang diinginkan perusahaan. pemasar berencana mengatur posisi produk mereka untuk dapat bersaing dengan produk sejenis.

Produk yang dijual diposisikan dengan harga yang terjangkau dan menyesuaikan dengan kebutuhan customer melalui konsultasi yang sudah dilakukan sebelumnya.

\section{Kebutuhan Manajemen \& Sumber Daya Manusia}

Dianalisa pada bisnis agar keseluruhan perencanaan manajemen dan sumber daya manusia dapat berjalan dengan baik. Aspek ini meliputi struktur organisasi perusahaan dan job description selain itu perencanaan standard dan operasional prosedur awal yang dibuat. 


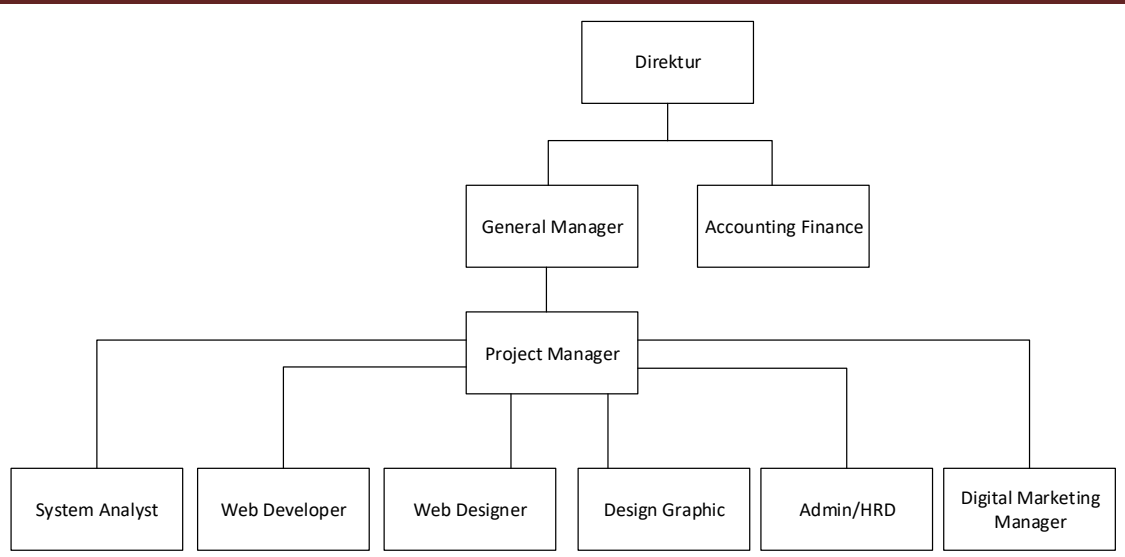

Gambar 1

Struktur Organisasi

Kebutuhan Investasi dan Modal Kerja Awal

Tujuan dilakukannya perencanaan keuangan untuk meminimalisir resiko kerugian yang sering terjadi di tahun pertama merintis usaha. Karena itu, agar bisnis yang akan dijalankan bisa berkembang dengan maksimal perlu dilakukan rencana keuangan.

Tabel 1

Neraca Saldo 2021

\begin{tabular}{|c|c|c|c|}
\hline \multicolumn{2}{|l|}{ Dalam (Rupiah) } & \multicolumn{2}{|l|}{ Dalam (Rupiah) } \\
\hline \multicolumn{2}{|l|}{ Aktiva } & \multicolumn{2}{|l|}{ Hutang } \\
\hline \multicolumn{2}{|l|}{ Aktiva Lancar } & Hutang Usaha & - \\
\hline Kas \& Bank & $4,420,610,000$ & & \\
\hline Biaya dibayar dimuka & $378,000,000$ & Total Hutang Lancar & - \\
\hline Office Suplies & $20,700,000$ & & \\
\hline \multirow[t]{2}{*}{ Total Aktiva Lancar } & $4,819,310,000$ & Ekuitas & \\
\hline & & Setor Modal Awal & $36,000,000,000$ \\
\hline \multicolumn{4}{|l|}{ Aktiva Tetap } \\
\hline Land & $9,600,000,000$ & Returned Earning & $220,310,000$ \\
\hline Building & $21,600,000,000$ & & \\
\hline Office Equipment & $1,080,000,000$ & & \\
\hline Akumulasi Depresiasi FA & $(1,089,000,000)$ & & \\
\hline Total Aktiva Tetap & $31,191,000,000$ & Modal & $3,000,000,000$ \\
\hline \multicolumn{4}{|l|}{ Other Assets: } \\
\hline Company License & $144,000,000$ & & \\
\hline Akumulasi Company License & $(66,000,000)$ & & \\
\hline Total other Assets & $210,000,000$ & & \\
\hline Total Aktiva & $36,220,310,000$ & Total Passiva & $36,220,310,000$ \\
\hline
\end{tabular}

\section{Payback Period (PP)}

Pengertian Payback Period menurut Dian Wijayanto (2012:247) adalah periode yang diperlukan untuk menutup kembali pengeluaran investasi (initial cash investment). Berdasarkan definisi dari Abdul Choliq dkk (2004), Payback Period adalah jangka waktu kembalinya investasi yang telah dikeluarkan, melalui keuntungan yang diperoleh dari suatu proyek yang telah direncanakan. Sedangkan menurut Bambang Riyanto (2004) Payback period adalah suatu periode yang diperlukan untuk dapat menutup kembali pengeluaran investasi dengan menggunakan proceeds atau aliran kas netto (net cash flows).

\section{Tabel 2}

Payback Period

\begin{tabular}{|l|l|l|}
\hline Tahun & Cashflow & Kumulatif \\
\hline IO & $(590,800,000.00)$ & $(590,800,000.00)$ \\
\hline OCF-1 & $389,512,500.00$ & $(201,287,500.00)$ \\
\hline OCF-2 & $535,162,500.00$ & $333,875,000.00$ \\
\hline OCF-3 & $461,700,000.00$ & $795,575,000.00$ \\
\hline OCF-4 & $536,550,000.00$ & $1,332,125,000.00$ \\
\hline OCF-5 & $1,688,634,000.00$ & $3,020,759,000.00$ \\
\hline
\end{tabular}

Dari Hasil perhitungan ditemukan nilai Payback Period 1.38. 
NPV

Net Present Value (NPV) adalah nilai dari semua arus kas masa depan (positif dan negatif) sepanjang masa investasi yang didiskontokan ke masa kini. Analisis NPV adalah bentuk penilaian intrinsik dan digunakan secara luas di seluruh keuangan dan akuntansi untuk menentukan nilai bisnis, keamanan investasi, proyek modal, usaha baru, program pengurangan biaya, dan apa pun yang melibatkan arus kas.

\section{Tabel 3}

NPV Positif \& NPV Negatif

\begin{tabular}{|l|l|l|}
\hline Tahun & NPV Positif & NPV Negatif \\
\hline 2021 & $347,779,017.086$ & $207,187,500.00$ \\
\hline 2022 & $426,628,268.49$ & $151,415,374.60$ \\
\hline 2023 & $328,628,940.42$ & $69,491,270.32$ \\
\hline 2024 & $340,987,224.97$ & $42,958,366.69$ \\
\hline 2025 & $958,176,281.08$ & $71,917,972.74$ \\
\hline Total & $1,811,399,733$ & $(47,829,516)$ \\
\hline
\end{tabular}

\section{IRR (Internal Rate of Return)}

IRR (Internal yang didapat berdasarkan formula:

IRR yang didapat 86.04

$$
I R R=i_{1}+\frac{N P V_{1}}{\left(N P V_{1}-N P V_{2}\right)}\left(i_{2}-i_{1}\right)
$$

\section{BEP (Break Even Point)}

Dari hasil analisis keuangan dan penetapan harga jual produk diketahui dengan penjualan per produk sebesar Rp.35.000.000,- maka hanya diperlukan penjualan 19 produk agar perusahaan mendapatkan BEP.

\section{KESIMPULAN}

Perencanaan keuangan yang menunjukan bahwa bisnis ini akan memberikan profit bagi investor dan layak untuk direalisasikan. Analisa keuangan instrument keuangan yang terdiri dari payback period yang menunjukan angka 1,38 sama dengan waktu maksimal yang ditetapkan, nilai NPV dengan nilai Rp. 1.811.399.733,- atau lebih besar dari nol menunjukkan investasi ini dapat menghasilkan tingkat penghasilan yang melebihi tingkat yang diminta dan nilai IRR sebesar $86 \%$ lebih tinggi dari suku bunga simpanan menunjukkan bahwa bisnis ini layak untuk diinvestasikan dan dijalankan.

\section{DAFTAR PUSTAKA}

Brigham, E. F. \& Houston, J. F. (2013). Fundamentals of Financial Management (13 ${ }^{\text {rd }}$ ed.). South-Western Cengage Learning.

Creating New Venture, Retrieved January 20,2020 from binus.ac.id website: https://sis.binus.ac.id/2018/03/20/creating-new-venture/

Drake, P. P. \& Fabozzi, F. J. (2010). The Basic of Finance: An Introduction to Financial Markets, Business Finance, and Portfolio Management. New Jersey, United States of America: John Wiley \& Sons Inc.

Ebert, R. J. \& Griffin, R. W. (2019). Pengantar Bisnis (10 ${ }^{\text {th }}$ ed.). Jakarta: Penerbit Erlangga.

King, D. L. (2008). Designing the Digital Experience: How to Use Experience Design Tools and Technijawques to Build Websites Customers Love, New Jersey, United States of America: Information Today, Inc.

Kotler, P., Kartajaya, H., \& Setiawan, I. (2017). Marketing 4.0 Moving From Traditional To Digital. New Jersey, USA: John Wiley \& Sons, Inc.

Kotler, P. \& Keller, K. L. (2012). Marketing Management (14th ed.). USA: Pearson International.

Mukharom, F. \& Sugianto, M. (2018). Tips Memulai Dan Mengembangkan Wirausaha IT. Bekasi, Jawa Barat: Excellent Publishing. 
Pearce, J. A. \& Robinson, R. B. (2013). Strategic Management Planning for Domestic \& Global Competition (14 ${ }^{\text {th }}$ ed.). New York, USA: McGraw Hill.

Potts, K. (2007). Web Design and Marketing Solutions for Business Websites. New York, United States of America: Apress.

Scarborough, N. M. (2011). Essentials of Entrepreneurship and Small Business Management ( $6^{\text {th }}$ ed.). New Jersey, United States of America: Prentice Hall.

Slamet, F., Tunjungsari, H. K., \& Mei, I. (2016). Dasar-dasar Kewirausahaan Teori dan Praktik ( $2^{\text {nd }}$ ed.). Jakarta: PT. Indeks.

Spinelli, S. \& Adams, R. (2012). New Venture Creation: Entrepreneurship for the $21^{\text {st }}$ Century ( ${ }^{\text {th }}$ ed.). New York, United States of America: McGraw-Hill, Irwin.

Suad, H. \& Pudjiastuti, E. (2015). Dasar-dasar Manajemen Keuangan ( ${ }^{\text {th }}$ ed.). Yogyakarta: Unit Penerbit dan Percetakan STIM YKPN (UPP STIM YKPN). 